\title{
Depression in Psoriatic Arthritis: Dimensional Aspects and Link with Systemic Inflammation
}

\author{
Ashish J. Mathew · Vinod Chandran
}

Received: March 18, 2020 / Published online: April 22, 2020

(C) The Author(s) 2020

\section{ABSTRACT}

Studying comorbidities in patients with psoriatic arthritis (PsA) provides a better understanding of the extended burden of the disease. Depression and anxiety are well recognized but understudied comorbidities in patients with

Digital Features To view digital features for this article go to: https://doi.org/10.6084/m9.figshare.12098052.

A. J. Mathew · V. Chandran $(\varangle)$

The Psoriatic Disease Program, Centre for Prognosis Studies in the Rheumatic Diseases, Krembil Research Institute, University Health Network, Toronto, Canada

e-mail: vinod.chandran@uhnresearch.ca

A. J. Mathew · V. Chandran

Division of Rheumatology, Department of

Medicine, University of Toronto, Toronto, Canada

V. Chandran

Department of Laboratory Medicine and

Pathobiology, University of Toronto, Toronto,

Canada

V. Chandran

Institute of Medical Science, University of Toronto,

Toronto, Canada

V. Chandran

Department of Medicine, Memorial University, St. John's, Canada

\section{A. J. Mathew}

Department of Clinical Immunology and

Rheumatology, Christian Medical College, Vellore, India
PsA. The prevalence of depression is significantly higher in this patient population than in the general population, with far reaching consequences in terms of long-term quality of life. Over the past few years there has been an increasing interest in the link between inflammation and depression, with several novel studies being conducted. Recent evidence suggests a significant improvement of depression in PsA patients treated with biologic disease-modifying anti-rheumatic drugs (bDMARDs) as compared to conventional DMARDs. Depression in PsA is multidimensional, with recognized phenotypes, including cognitive disorder, alexithymia and anhedonia. The paucity of standardized, validated tools to screen these dimensional phenotypes remains an unmet need. Prevalence studies on depression in patients with PsA, mostly based on patient-reported outcomes, are only able to highlight the tip of the iceberg. A comprehensive, multi-disciplinary approach addressing the subdomains of depression is imperative for a better understanding of depression in PsA patients, as well as to find a way forward for improving their quality of life. In this scoping review, we explore existing evidence on the burden of depression in PsA patients, the link between inflammation and depression in these patients and the screening tools used to evaluate the subdomains of depression. 


\section{PLAIN LANGUAGE SUMMARY}

Psoriatic arthritis (PsA) is a chronic, deforming arthritis associated with the skin condition psoriasis. A large number of patients with PsA are known to have another co-existing chronic disease, which adds to their overall disease burden and affects their quality of life. Depression is a common illness known to co-exist in about $20 \%$ of patients with PsA. Inflammation is a common factor between psoriatic arthritis and depressive disorders and is thought to play an important role in depression ocurring in these patients. Recent research in the field has revealed that different dimensions of depression, such as the inability to feel pleasure, loss of intellectual functions and difficulty identifying and expressing emotions, may contribute to the overall disease. It is important to screen for these dimensions while assessing PsA patients with depression. Most of the studies conducted to date have based the diagnosis of depression on self-reported questionnaires. In this article we describe the relation between inflammation and different dimensions of depression in patients with PsA and set out a feasible screening method for depression. A good understanding of depression in patients with PsA will be useful in designing treatment strategies.

Keywords: Comorbidities; Inflammation; Psoriatic arthritis

Depression;

\section{Key Summary Points}

Depression and anxiety are seen in around one third of patients with psoriatic arthritis (PsA), and have a bidirectional association with pain.

Inflammation is considered to be a core pathogenic feature of depression in PsA patients.

A renewed interest in the interaction between pain and the dimensional aspects of depression (e.g. anhedonia, cognitive dysfunction and alexythemia) has helped in understanding distinct depression phenotypes.
A comprehensive assessment of depression in PsA patients should incorporate screening tools to detect the dimensional aspects.

Use of antidepressants in PsA patients with depression may be tailored based on the distinct phenotype.

\section{INTRODUCTION}

Psoriatic arthritis (PsA) is a chronic, progressive, inflammatory arthritis associated with cutaneous psoriasis that can potentially affect multiple organ systems. It is seen in about $24 \%$ of patients with cutaneous psoriasis. Psoriatic disease is often restrained within the core clinical domains such as skin psoriasis, nail involvement, peripheral inflammatory arthritis, axial spondyloarthritis, enthesitis and dactylitis, while its myriad systemic effects and comorbidities are overlooked [1-3]. Over the years there has been mounting evidence on the effects of PsA extending beyond skin and joint diseases, including cardiovascular disease, diabetes, obesity, metabolic syndrome, osteoporosis, malignancy, fatty liver disease, depression and anxiety [4]. Patients with PsA tend to have a significantly higher burden of comorbidity than do patients with psoriasis alone and the nonPsA population $[5,6]$, and these comorbidities pose an incremental burden on their long-term quality of life [7]. Compared to the metabolic comorbidities, depression as a comorbidity in PsA has not been well studied. The psycho-social burden of PsA has been shown to bear a negative impact on the quality of life [8]. In patients with psoriasis, psychiatric disorders can both result from and contribute to disease progression, suggesting overlapping biological mechanisms [9]. The synthesis of psoriasis and destructive inflammatory arthritis in PsA patients should arguably lead to a higher point prevalence of comorbid depression and anxiety. However, the cause and effect relationship of depression and PsA is often arduous to gauge and contributes to the sparsity of data. 
In this review we examine the link between depression and PsA, focusing on the different facets of depression and its long-term effects. Evaluation of depression in patients with PsA, its link with systemic inflammation and unmet needs with regards to its phenotyping and management strategies will also be discussed.

\section{METHODS}

Databases of MEDLINE using the PubMed and Ovid platforms, Scopus and Directory of Open Access Journals were probed to review the burden of depression in patients with PsA. Searches were conducted using keywords, including "depression," "anxiety," "psoriatic arthritis," "psychosocial burden" and "quality of life." Search results were supplemented by reference citations from notable reviews on this topic and from articles identified in initial searches. A descriptive review of findings from the literature search was conducted, and the authors' interpretation is provided.

This article is based on previously conducted studies and does not contain any studies with human participants or animals performed by any of the authors.

\section{THE PREVALENCE OF DEPRESSION AND ANXIETY IN PATIENTS WITH PSORIATIC ARTHRITIS}

The past decade has seen a rise in studies investigating the burden of mental illness comorbidities in patients with PsA. Bandinelli et al. investigated 100 early PsA patients using the Hospital Anxiety and Depression scale (HADS), comparing the scores to those of 50 healthy controls, 50 late PsA patients and 50 other SpA patients, matching for age, sex and body mass index. "Possible" anxiety and depression were reported in 29 and $26 \%$ of patients, respectively, and the "probability" of developing anxiety and depression was noted in 14 and $11 \%$ of patients, respectively [10]. Analysis of data from the University of Toronto PsA cohort in which 306 patients with PsA and 135 patients with psoriasis were compared using
HADS and the standard clinical protocol revealed a prevalence of 36.6 and $22.2 \%$ for anxiety and depression, respectively. The prevalence of both anxiety and depression in this cohort was $17.7 \%$. The rate of depression was higher in the PsA than in the psoriasis patients [11]. Wu et al. compared the risk of depression in patients with psoriasis, patients with PsA and the general population and reported that it was 14 and $22 \%$ higher in patients with psioriasis and PsA, respectively than in the general population [12]. In a multicenter cross-sectional study in Spain. Freire et al. reported a prevalence of anxiety and depression of 29.7 and $17.6 \%$, respectively, in 495 patients with PsA [13]. A recent systematic review reports a prevalence of depression in patients with PsA ranging from 5 to $51 \%$, depending on the thresholds used, with $20 \%$ of patients reported as having at least mild depression and 14\% reported as having at least moderate depression; the pooled prevalence of at least moderate depression was 14\% [14]. Another systematic review on depression and anxiety in PsA patients from three studies included in the analysis describes a pooled prevalence of depression ranging from 9 to $22 \%$, and of anxiety ranging from 15 to $30 \%$ [15].

\section{THE CONSEQUENCE OF DEPRESSION/ANXIETY IN PATIENTS WITH PSORIATIC ARTHRITIS}

Lewinson et al. report major depressive disorder (MDD) as a significant risk factor (hazard ratio $1.37,95 \%$ confidence interval 1.05-1.8, $p=0.021$ ) for developing PsA in a longitudinal cohort of psoriasis patients followed up to 25 years until the development of PsA or the censor date [16]. Anxiety in PsA patients has an independent association with quality of life, thus accentuating the need for its proper screening and management [17]. Depression was found to have a profound effect on the health-related quality of life in patients with PsA in the Nordic Patient Survey of Psoriasis and 
Psoriatic Arthritis (NORPAPP) [18]. A large study from the UK described an increase in deaths attributable to suicide in patients with PsA, as compared to the general population [19]. Although another study from the USA could not conclude any increased risk of suicidal ideation or suicide attempt in patients with PsA when compared to the general population, the authors did note a higher risk of "any suicidality"-a combined endpoint encompassing suicidal ideation and suicidal attempts [12].

\section{DECIPHERING THE LINK BETWEEN DEPRESSION AND PSORIATIC ARTHRITIS}

The cause-effect relationship between depression and PsA is difficult to decrypt. There is compelling evidence suggesting the role of inflammatory responses in the pathophysiology of depression, as manifested by the overexpression of proinflammatory cytokines, acute phase reactants and chemokines in patients with major depression who are otherwise medically healthy [20]. Inflammation has been increasingly explored as an important factor linking the complex relationship between depression and chronic medical illness [21]. Levels of proinflammatory cytokines involved in the pathogenesis of PsA, such as interleukin (IL)-6, IL-17 and tumor necrosis factor-alpha (TNF $\alpha$ ), are raised in patients with depression and anxiety [8]. Patients with autoimmune diseases are, when treated with inflammation-based therapies such as interferon or certain vaccinations, at a higher risk of developing mood disorders [22]. However, much as inflammation is considered to be central to the pathogenesis of depression in PsA, inflammation in itself cannot explain the complete link, with some studies failing to find an association between depression and inflammation [23, 24]. Kim et al. studied the effect of the IL-23 and IL-17 axis on major depression by measuring the levels of these cytokines in 26 patients with MDD and in 28 age- and sex-matched normal controls both before and after 6 weeks of treatment with antidepressants [25]. These authors reported that the baseline levels of these cytokines in the
MDD patient group were not significantly different from those of the normal controls and that there was also no difference in the levels after 6 weeks of therapy, results which conflict with the cytokine theory of MDD [25]. This study is important in the context of anti-IL-17 therapies being used in the treatment of PsA. A meta-analysis by Hannestad et al. in which all available data on changes in serum levels of TNF- $\alpha$, IL- 6 and/or IL-1 $\beta$ during antidepressant therapy were pooled did not show a reduction in the levels of TNF- $\alpha$, but did show reduced levels of IL-1 $\beta$ and possibly IL-6. Serotonin uptake inhibitors were shown to reduce the levels of IL- 6 and TNF $\alpha$; other antidepressants did not [26].

The role of hypothalamic-pituitary-adrenal (HPA) axis hyperactivity has been proposed in the context of a link between psychiatric stress and an inflammatory immune response activating cell-mediated autoimmunity and triggering chronic inflammation, as seen in psoriasis patients [27]. HPA hyperactivity, commonly seen in depression, leads to the release of high levels of corticotropin-releasing hormone (CRH) and cortisol [28]. CRH signaling has been suggested to play a role in pathologic mechanisms associated with joint inflammation in arthritis [29]. Although the exact mechanism is still unknown, there seems to be a bidirectional relationship between PsA and depression.

\section{DEPRESSION HAS A BIDIRECTIONAL ASSOCIATION WITH PAIN IN PATIENTS WITH PSORIATIC ARTHRITIS}

The interaction between depression and pain, often labeled as the depression-pain syndrome, has been the nucleus of a growing body of literature [30]. The bidirectional hypothesis suggesting a common pathophysiology for both these disorders has been tested in rheumatic diseases, with conflicting results [31, 32]. Husted et al. evaluated the relationship of depressive symptoms and pain with the changes in inflammatory joint activity in 394 patients with PsA and noted a small but consequential 
bidirectional relationship between depressive symptoms and pain [33]. These results indicate that pain from PsA and depressive symptoms are inter-connected and point to a common inflammatory etiology for both. Pro-inflammatory cytokines associated with PsA are associated with symptoms of depression and anxiety $[34,35]$. Previous studies have drawn attention to the higher morbidity and mortality in patients with comorbid pain and depression compared to those with either condition alone [36-38]. Depression leads to sensitization and plays a pivotal role in the shaping of pain responses and outcomes [39].

\section{EFFECT OF TREATMENT ON PSA PATIENTS WITH COMORBID DEPRESSION}

Response to therapy in PsA patients with comorbid depression is poor. The cause for this is often multi-factorial. Michelsen et al. reviewed the Norwegian Disease-Modifying Anti-Rheumatic Drugs (NOR-DMARD) registry with the aim to investigate the predictive value of baseline depression on the probability of achieving joint remission in rheumatoid arthritis and PsA patients [40]. Based on scores of $\leq 56$ on the Medical Outcomes Study Short Form-36 (SF-36) mental health (MH) domain and $\leq 38$ on the SF-36 mental health component (MHC) summary, baseline depression and anxiety were negative predictors at 3 and 6 months for achieving a Disease Activity in Psoriatic Arthritis (DAPSA) score of $\leq 4$. Depression and anxiety were not associated with inflammatory markers and swollen joint count during follow-up [40]. Adherence to treatment is more difficult in PsA patients with comorbid depression, which interferes with treat-to-target strategies and the achievement of a minimal disease activity state [41]. A study using data from the Danish Biological Registry (DANBIO), which included 1750 patients with PsA, noted that patients with depression and/or anxiety showed shorter persistence on TNF inhibitors (TNFi) than did those without comorbidities [42]. In a British cohort study of 566 PsA patients, the presence of pre-specified comorbidities, including depression, at baseline was associated with significantly higher TNFi discontinuation rates [43]. Physicians should also remain cognizant of the close link between chronic widespread pain and depression while planning treatment strategies in patients with PsA. Composite disease activity measures include tender joint count and patient global visual analogue scales that may be high despite the absence of joint inflammation in patients with comorbid depression. Setting sight on tight control of PsA activity using such measures in these situations risks inappropriate escalation of therapy, which may lead to more adverse events. Clinical judgement of the degree of disease activity is always important.

The reported increased rate of depression and suicidal ideations with some of the newer biologic and targeted DMARDs used for treating psoriatic disease needs to be evaluated. Brodalumab, a fully human anti-IL17 receptor A inhibitor, is approved for the treatment of moderate to severe plaque psoriasis. However, concerns regarding suicidal ideation and behavior during phase III clinical trials in PsA led to early termination of all studies and a boxed warning being added to the monograph of the drug [44]. This concern was explored in great detail, as similar adverse events were not reported in any of the other IL-17 inhibitors, including secukinumab or ixekizumab. Patients with a history of psychiatric disorders or substance abuse were included in the brodalumab trial, in contrast with trials on IL-17 inhibitors, which had excluded them [45]. Similar concerns were raised with apremilast, a selective phosphodiesterase- 4 inhibitor approved for the treatment of psoriasis and PsA [46]. However, a long-term experience study with apremilast in PsA patients did not observe any safety signals pertaining to suicidal risks [47]. Nevertheless, given the increased risk of depression in patients with psoriatic disease it is important for treating physicians to be appraised of these observations and engage in a candid and ongoing conversation with patients that leads to an informed and shared decision on therapy. The labels of both brodalumab (black box warning) and apremilast carry a warning about suicidal ideation and depression. 


\section{BIOLOGIC DISEASE-MODIFYING ANTI-RHEUMATIC DRUGS IN THE TREATMENT OF DEPRESSION}

Psoriatic arthritis patients with depression are often prescribed antidepressants along with DMARDs. The effect of these medications on depression either in combination or separately may be worth exploring. A recent study from a Swedish registry evaluated the use of antidepressants and benzodiazepine-related hypnotics in patients with rheumatoid arthritis (RA), PsA and ankylosing spondylitis. Prior to starting treatment with DMARDs, the rates of psychotropic substance medicines had increased among the patients, comparable to the rates among the matched population control subjects. However, after initiation of DMARDs, the rates of antidepressant medicines diminished, or leveled out, while the increase among the control group continued [48]. This reduction in the use of antidepressants could be due to a direct or indirect treatment effect. Mitigation of pain and disease activity with DMARDs, which in turn leads to enhancement of mood and sleep cycle could be another explanation. In patients with RA, blockade of the TNF pathway has been shown to modulate serotonin transporter expression, a key target of conventional antidepressant therapy [49]. The synergistic effect of DMARDs and antidepressants needs to be studied further. In this context it is also important to be mindful of the placebo effects in the treatment of depression and anxiety, as analyses of the majority of published clinical trial data on antidepressants demonstrate that the difference in improvement between drug and placebo is not clinically meaningful [50].

The cytokine theory of depression, greeted with much enthusiasm, has led to biomarkerguided anti-inflammatory therapies being investigated in MDD patients. Two clinical trials in this regard are noteworthy. Raison et al. studied the effect of infliximab on depressed mood in patients with treatment-resistant depression. Although the study failed to achieve its primary outcome, findings suggestive of a favorable outcome in patients with raised baseline C-reactive protein were noted [51]. This was followed by another clinical trial on infliximab in which patients had to meet certain biochemical or phenotypic inclusion criteria that indicated a state of inflammatory activation at baseline. Infliximab did not reduce symptoms of depresssion compared to placebo in the 60 patients with bipolar depression included in the study [52]. As attractive as this theory appears, realization of the promise of precision medicine for treating MDD has been dismal to date.

On the contrary, the effect of biologics on depression in patients with psoriasis has been encouraging. Randomized controlled trials on adalimumab, etanercept and ustekinumab are associated with a statistically significant reduction in depressive symptom scores using different scales in patients with moderate to severe psoriasis [53]. In a nationwide cohort study from Taiwan consisting of 980 patients with PsA or psoriasis, $\mathrm{Wu}$ et al. examined the effects of biologic therapy on reducing depression and insomnia rates and attempted to identify the subgroups of patients who would benefit from biologic therapy. The prevalence of patients on antidepressants before biologic therapy was $20 \%$. The authors noted a reduction of more than $40 \%$ in this prevalence rate 2 years after biologic therapy. The stratified analysis revealed a more rapid and significant reduction in depression in patients aged $<45$ years who took continuous biologics and in those who did not have PsA [54].

In summary, the pain and higher inflammation in PsA patients, which are interlinked with depression, seem to be intractable constructs in the treatment of PsA with biologic therapies. This may also explain the differential outcomes in patients with PsA and psoriasis being treated with biologic therapy.

\section{DEPRESSION IN PSORIATIC ARTHRITIS IS MULTI-DIMENSIONAL WITH DISTINCT PHENOTYPES}

With a better understanding of MDD, there has been a renewed interest in the interaction of pain with other subdomains of depression, such 
as anhedonia, cognitive deficits and alexithymia. Depression is multi-dimensional, and it is often challenging to obtain a snapshot of the entire spectrum. Most of the assessment tools of these subdomains are self-reported questionnaires, and it is important to include these tools in the overall assessment of depression in PsA patients in order to understand the bigger picture (Table 1 ).

There is a growing body of evidence on the broad cognitive deficits associated with impaired daily and psychosocial functioning in MDD [67]. Di Carlo et al. assessed the prevalence of mild cognitive impairment in 96 patients with PsA and reported that short-term memory was the most prevalent affected domain, present in the patient population at a rate of $48.9 \%$ [66]. TNF $\alpha$ has been shown to play a critical role in cognitive dysfunction associated with MDD [68]. Cognitive dysfunctions can be used to prognosticate at-risk individuals and monitor progression. However, a comprehensive tool to assess cognitive deficits is lacking. The THINC-integrated tool (THINC-it) is a validated, computerized cognitive assessment system that screens both objective and subjective cognitive deficits in MDD [69]. Other validated tools used to assess objective and subjective cognitive impairment in MDD include the Screen for Cognitive Impairment in Psychiatry (SCIP-D) and the Cognitive Complaints in Bipolar Disorder Assessment (COBRA) [70]. Assessment of cognitive impairment should be an integral part of the assessment and treatment of MDD [71, 72].

Anhedonia, defined as the diminished ability to experience pleasure or enjoy previously pleasurable activities, is a diagnostic feature of depression and shown to be a predictor of antidepressant nonresponse [73, 74]. Validated self-reported measures for anhedonia used in clinical research include the Snaith-Hamilton Pleasure Scale (SHAPS), the Fawcett-Clark Pleasure Capacity Scale (FCPS), the Revised Chapman Physical Anhedonia Scale (CPAS) and the Chapman Social Anhedonia Scale (CSAS) [75].

Alexithymia is a disorder of emotion regulation mechanisms that presents as a dissociation of emotional and physical responses to life events and bodily sensations [76]. Li et al. performed a meta-analysis of studies including 3572 subjects and highlighted a moderate correlation of alexithymia scores with the severity of depression [77]. In a more recent study, Chimenti et al. assessed the prevalence of alexithymia in 50 patients with RA and 51 with PsA using the Toronto Alexithymia Scale (TAS-20), a self-reported questionnaire. Alexithymia was noted in $33.3 \%$ of patients with PsA [78]. Other tools used to determine alexithymia include the Bermond-Vorst Alexithymia Questionnaire (BVAQ), the Toronto Structured Interview for Alexithymia (TSIA) and the modified Beth Israel Hospital Questionnaire (BIHQ) [79].

\section{SCREENING TOOLS FOR DETECTING DEPRESSION IN PSA STUDIES MISS THE BIG PICTURE}

The diagnosis of depression in prevalence studies among PsA patients is mostly based on self-reported questionnaires. These questionnaires do not delve into the multifaceted nature of depression. The dynamic nature of depression adds to this conundrum. The common screening tools used to report depression and anxiety include HADS, Patient Health Questionnaire 9-item scale (PHQ-9), Generalized Anxiety Disorder scale (GAD-7) and the SF-36 MCS and SF-36 MH [14]. A systematic screening method encompassing crucial constructs like cognitive dysfunction and anhedonia in PsA patients may be able to capture depression more comprehensively. This will guide therapeutic decisions as the subdomains of depression may respond differentially to treatment $[80,81]$.

\section{NEUROIMAGING AUGMENTS THE SCREENING TOOLS IN DEFINING DEPRESSION}

The field of brain imaging over the last decade has enhanced our understanding of depression in general. Neuroimaging, mostly using magnetic resonance imaging (MRI) can aid in phenotyping comorbid depression, the discovery of 
Table 1 Comprehensive screening tools for depression in psoriatic arthritis

\begin{tabular}{|c|c|c|c|c|c|}
\hline \multirow{2}{*}{$\begin{array}{l}\text { Dimensional } \\
\text { phenotype }\end{array}$} & \multirow[t]{2}{*}{ Screening tool } & \multicolumn{4}{|c|}{ PsA studies using the tool } \\
\hline & & $\begin{array}{l}\text { First } \\
\text { Author }\end{array}$ & Year & $\begin{array}{l}\text { Study } \\
\text { type }\end{array}$ & References \\
\hline \multirow{20}{*}{$\begin{array}{l}\text { Overall } \\
\text { depression }\end{array}$} & \multirow{4}{*}{$\begin{array}{l}\text { Medical Outcomes Study Short Form-36 (SF-36) Mental } \\
\text { Component Summary (MCS) and Mental Health (MH) } \\
\text { domains }\end{array}$} & Strand & 2012 & RCT & {$[55]$} \\
\hline & & Rosen & 2012 & CS & {$[56]$} \\
\hline & & Michelsen & 2017 & CS & {$[40]$} \\
\hline & & Gladman & 2014 & RCT & {$[57]$} \\
\hline & \multirow[t]{7}{*}{ Hospital Anxiety and Depression scale (HADS) } & Gniadecki & 2011 & RCT & {$[58]$} \\
\hline & & Freire & 2011 & CS & {$[13]$} \\
\hline & & Bandinelli & 2013 & CS & {$[10]$} \\
\hline & & McDonough & 2014 & CS & {$[11]$} \\
\hline & & Meesters & 2014 & CS & {$[59]$} \\
\hline & & Howells & 2018 & CS & {$[60]$} \\
\hline & & Strober & 2018 & CS & {$[61]$} \\
\hline & \multirow[t]{3}{*}{ Patient Health Questionnaire 9-item scale (PHQ-9) } & Kotsis & 2012 & CS & {$[62]$} \\
\hline & & Lamb & 2017 & CS & {$[63]$} \\
\hline & & $\mathrm{Wu}$ & 2017 & CS & {$[12]$} \\
\hline & Generalized Anxiety Disorder scale (GAD-7) & Lamb & 2017 & CS & {$[63]$} \\
\hline & Beck's depression inventory (BDI) & Milutinovic & 2019 & CS & {$[64]$} \\
\hline & \multirow{4}{*}{$\begin{array}{l}\text { World Health Organization International Classification of } \\
\text { Diseases (ICD), 9th revision, } 10 \text { codes }\end{array}$} & $\mathrm{Wu}$ & 2016 & CS & {$[54]$} \\
\hline & & Ballegaard & 2017 & CS & {$[42]$} \\
\hline & & Löfvendahl & 2018 & CS & {$[65]$} \\
\hline & & Kaine & 2019 & CS & {$[6]$} \\
\hline \multirow{5}{*}{$\begin{array}{l}\text { Cognitive } \\
\text { disorder }\end{array}$} & Montreal Cognitive Assessment (MoCA) & Di Carlo & 2019 & CS & {$[66]$} \\
\hline & THINC-Integrated Tool (THINC-it) & \multirow{4}{*}{\multicolumn{4}{|c|}{ No studies in PsA }} \\
\hline & Mini-Cog & & & & \\
\hline & Screen for Cognitive Impairment in Psychiatry (SCIP-D) & & & & \\
\hline & $\begin{array}{l}\text { Cognitive Complaints in Bipolar Disorder Assessment } \\
\text { (COBRA) }\end{array}$ & & & & \\
\hline \multirow[t]{4}{*}{ Anhedonia } & Snaith-Hamilton Pleasure Scale (SHAPS) & \multirow{4}{*}{\multicolumn{4}{|c|}{ No studies in PsA }} \\
\hline & Fawcett-Clark Pleasure Capacity Scale (FCPS) & & & & \\
\hline & Revised Chapman Physical Anhedonia Scale (CPAS) & & & & \\
\hline & Chapman Social Anhedonia Scale (CSAS) & & & & \\
\hline
\end{tabular}


Table 1 continued

\begin{tabular}{|c|c|c|c|c|c|}
\hline \multirow{2}{*}{$\begin{array}{l}\text { Dimensional } \\
\text { phenotype }\end{array}$} & \multirow[t]{2}{*}{ Screening tool } & \multicolumn{4}{|c|}{ PsA studies using the tool } \\
\hline & & $\begin{array}{l}\text { First } \\
\text { Author }\end{array}$ & Year & $\begin{array}{l}\text { Study } \\
\text { type }\end{array}$ & References \\
\hline \multirow[t]{4}{*}{ Alexithymia } & Toronto Alexithymia Scale (TAS-20) & Chimenti & 2019 & CS & {$[78]$} \\
\hline & Bermond-Vorst Alexithymia Questionnaire (BVAQ) & & & & \\
\hline & Toronto Structured Interview for Alexithymia (TSIA) & & & & \\
\hline & Modified Beth Israel Hospital Questionnaire (BIHQ) & & & & \\
\hline \multirow[t]{4}{*}{ Neuroimaging } & Structural magnetic resonance imaging (MR)I & \multirow{3}{*}{\multicolumn{4}{|c|}{ No studies in PsA }} \\
\hline & Functional MRI & & & & \\
\hline & MR spectroscopy & & & & \\
\hline & Positron emission tomography (PET) scan & & & & \\
\hline
\end{tabular}

Ps $A$ Psoriatic arthritis

a Study type: CS, Cohort study; RCT, randomized controlled trial

diagnostic and prognostic biomarkers, and eventually translate to precision medicine. Structural MRI (sMRI), functional MRI (fMRI) and positron emission tomography are the various neuroimaging modalities described [82]. fMRI has shown activity changes and increased connectivity over brain regions implicated in self-relation and cognitive tasks, respectively $[83,84]$. sMRI helps in identifying hippocampal volume, which has been shown to be reduced in patients with MDD [85]. The cognitive decline seen in MDD has been proposed to be due to reduction in hippocampal volume [86]. Magnetic resonance spectroscopy has demonstrated reduced levels of glutamate, glutamine and gamma-aminobutyric acid in depressed patients [87]. Utility of these modalities in a clinical setting, however, may be limited.

\section{FUTURE PERSPECTIVES}

Given the renewed interest in pathogenesis, assessment and therapeutic options, the future of treating comorbid depression in patients with PsA looks promising. While novel hypotheses for pathogenesis are being identified, a comprehensive assessment of depression in PsA patients is pivotal in planning treatment. A well-designed study in patients with PsA that incorporates an assessment of various constructs of depression is yet to be done. We propose a comprehensive study in three phases to identify the associations between disease severity, dimensional disturbances of depression and brain imaging abnormalities in patients with PsA. In the first phase, data on outcomes of depression and anxiety symptomatology should be collected through self-reported questionnaires, including the SHAPS, Generalized Anxiety Disorder (GAD-7) scale and the Quick Inventory of Depressive Symptomatology (SelfReport) (QIDS-SR). These data should be augmented in the second phase by structured interviews applying the Montgomery-Asberg Depression Rating Scale (MADRS) and and assessment of cognitive function using the THINC-it tool [88-91]. The third phase should comprise neuroimaging by structural and functional magnetic resonance imaging modalities to assess central nervous system volume and functional connectivity alterations.

The results from this study should inform a well-designed clinical trial of biologic therapy, targeting different constructs of depression. 


\section{CONCLUSIONS}

The intricate relationship between comorbid depression and systemic inflammation and disease manifestations in patients with PsA is still being deciphered. Novel mechanisms tying the loose threads of depression, psoriatic disease, pain and inflammation together need to be evaluated, potentially translating to drug discovery. Physicians should be conversant with the comprehensive assessment of the subdomains of depression as this knowledge will effectively enhance remission rates and the quality of life in patients with PsA.

\section{ACKNOWLEDGEMENTS}

Funding. No funding or sponsorship was received for this study or publication of this article.

Authorship. All named authors meet the International Committee of Medical Journal Editors (ICMJE) criteria for authorship for this article, take responsibility for the integrity of the work as a whole, and have given their approval for this version to be published.

Disclosures. Ashish J. Mathew is supported by a National Psoriasis Foundation Psoriatic Disease Research Fellowship. The Psoriatic Disease Program is supported by the Krembil Foundation. Vinod Chandran has nothing to disclose.

Compliance with Ethics Guidelines. This article is based on previously conducted studies and does not contain any studies with human participants or animals performed by any of the authors.

Data Availability. Data sharing is not applicable to this article as no datasets were generated or analysed during the current study.

Open Access. This article is licensed under a Creative Commons Attribution-NonCommercial 4.0 International License, which permits any non-commercial use, sharing, adaptation, distribution and reproduction in any medium or format, as long as you give appropriate credit to the original author(s) and the source, provide a link to the Creative Commons licence, and indicate if changes were made. The images or other third party material in this article are included in the article's Creative Commons licence, unless indicated otherwise in a credit line to the material. If material is not included in the article's Creative Commons licence and your intended use is not permitted by statutory regulation or exceeds the permitted use, you will need to obtain permission directly from the copyright holder. To view a copy of this licence, visit http://creativecommons.org/licenses/by$\mathrm{nc} / 4.0 /$.

\section{REFERENCES}

1. Alinaghi F, Calov M, Kristensen LE, et al. Prevalence of psoriatic arthritis in patients with psoriasis: a systematic review and meta-analysis of observational and clinical studies. J Am Acad Dermatol. 2019;80:251-65.

2. Ritchlin CT, Colbert RA, Gladman DD. Psoriatic arthritis. N Engl J Med. 2017;376:957-70.

3. Ogdie A, Schwartzman S, Eder L, et al. Comprehensive treatment of psoriatic arthritis: managing comorbidities and extraarticular manifestations. J Rheumatol. 2014;41:2315-22.

4. Husni ME. Comorbidities in psoriatic arthritis. Rheum Dis Clin North Am. 2015;41:677-98.

5. Husted JA, Thavaneswaran A, Chandran V, et al. Cardiovascular and other comorbidities in patients with psoriatic arthritis: a comparison with patients with psoriasis. Arthritis Care Res. 2011;63:1729-35.

6. Kaine J, Song X, Kim G, Hur P, Palmer JB. Higher incidence rates of comorbidities in patients with psoriatic arthritis compared with the general population using U.S. administrative claims data. J Manag Care Spec Pharm. 2019;25:122-32.

7. Husted JA, Thavaneswaran A, Chandran V, Gladman DD. Incremental effects of comorbidity on quality of life in patients with psoriatic arthritis. J Rheumatol. 2013;40:1349-56. 
8. Husni ME, Merola JF, Davin S. The psychosocial burden of psoriatic arthritis. Semin Arthritis Rheum. 2017;47:351-60.

9. Ferreira BI, Abreu JL, Reis JP, Figueiredo AM. Psoriasis and associated psychiatric disorders: a systematic review on etiopathogenesis and clinical correlation. J Clin Aesthet Dermatol. 2016;9:36-43.

10. Bandinelli F, Pringnano F, Bonciani D, et al. Clinical and demographic factors influence on anxiety and depression in early psoriatic arthritis. Clin Exp Rheumatol. 2013;31:318-9.

11. McDonough E, Ayearst R, Eder L, et al. Depression and anxiety in psoriatic disease: prevalence and associated factors. J Rheumatol. 2014;41:887-96.

12. Wu JJ, Penfold RB, Primatesta P, et al. The risk of depression, suicidal ideation and suicide attempt in patients with psoriasis, psoriatic arthritis or ankylosing spondylitis. J Eur Acad Dermatol Venereol. 2017;31:1168-75.

13. Freire M, Rodriguez J, Moller I, et al. Prevalence of symptoms of anxiety and depression in patients with psoriatic arthritis attending rheumatology clinics. Rheumatol Clin. 2011;7:20-6.

14. Zhao SS, Miller N, Harrison N, Duffield SJ, Dey M, Goodson NJ. Systematic review of mental health comorbidities in psoriatic arthritis. Clin Rheumatol. 2020;39:217-25.

15. Kamalaraj N, El-Haddad C, Hay P, Pile K. Systematic review of depression and anxiety in psoriatic arthritis. Int J Rheum Dis. 2019;22:967-73.

16. Lewinson RT, Vallerand IA, Lowerison MW, et al. Depression is associated with an increased risk of psoriatic arthritis among patients with psoriasis: a population-based study. J Invest Dermatol. 2017;137:828-35.

17. Baviere W, Deprez X, Houvenagel E, et al. Association between comorbidities and quality of life in psoriatic arthritis: results from a multicentric crosssectional study (PSAQUAL study). J Rheumatol 2020;47(3):369-76.

18. Duvetorp A, Østergaard M, Skov L, et al. Quality of life and contact with healthcare systems among patients with psoriasis and psoriatic arthritis: results from the NORdic PAtient survey of Psoriasis and Psoriatic arthritis (NORPAPP). Arch Dermatol Res. 2019;311:351-60.

19. Ogdie A, Maliha S, Shin D, et al. Cause-specific mortality in patients with psoriatic arthritis and rheumatoid arthritis. Rheumatology (Oxford). 2017;56:907-11.
20. Raison CL, Capuron L, Miller AH. Cytokines sing the blues: inflammation and the pathogenesis of depression. Trends Immunol. 2006;27:24-31.

21. Kramer NE, Cosgrove VE, Dunlap K, Subramaniapillai M, McIntyre RS, Suppes T. A clinical model for identifying an inflammatory phenotype in mood disorders. J Psych Res. 2019;113:148-58.

22. Walker JR, Graff LA, Dutz JP, Bernstein CN. Psychiatric disorders in patients with immune-mediated inflammatory diseases: prevalence, association with disease activity, and overall patient wellbeing. J Rheumatol Suppl. 2011;88:31-5.

23. Haack M, Hinze-Selch D, Fenzel T, et al. Plasma levels of cytokines and soluble cytokine receptors in psychiatric patients upon hospital admission: effects of confounding factors and diagnosis. J Psychiatr Res. 1999;33:407-18.

24. Steptoe A, Kunz-Ebrecht SR, Owen N. Lack of association between depressive symptoms and markers of immune and vascular inflammation in middleaged men and women. Psychol Med. 2003;33: 667-74.

25. Kim J-W, Kim Y-K, Hwang J-A, et al. Plasma levels of IL-23 and IL-17 before and after anti-depressant treatment in patients with major depressive disorder. Psychiatry Investig. 2013;10:294-9.

26. Hannestad J, DellaGioia N, Bloch M. The effect of antidepressant medication treatment on serum levels of inflammatory cytokines: a meta-analysis. Neuropsychopharmacology. 2011;36:2452-9.

27. Vreeburg SA, Hoogendijk WJ, van Pelt J, et al. Major depression disorder and hypothalamic-pituitaryadrenal axis activity: results from a large cohort study. Arch Gen Psychiatry. 2009;66:617-26.

28. Arborelius L, Owens MJ, Plotsky PM, Nemeroff CB. The role of corticotropin-releasing factor in depression and anxiety disorders. J Endocrinol. 1999;160:1-12.

29. McEvoy AN, Bresnihan B, FitzGerald O, Murphy EP. Corticotropin-releasing hormone signalling in synovial tissue from patients with early inflammatory arthritis is mediated by the type $1 \alpha$ corticotropin-releasing hormone receptor. Arthritis Rheum. 2001;44:1761-7.

30. Bair MJ, Robinson RL, Katon W, Kroenke K. Depression and pain, comorbidity: a literature review. Arch Intern Med. 2003;163:2433-45.

31. Schieir O, Thombs BD, Hudson M, et al. Symptoms of depression predict the trajectory of pain among patients with early inflammatory arthritis: a path 
analysis approach to assessing change. J Rheumatol. 2009;36:231-9.

32. Evers AW, Kraaimaat FW, Geenen R, Jacobs JW, Bijlsma JW. Longterm predictors of anxiety and depressed mood in early rheumatoid arthritis: a 3 and 5-year followup. J Rheumatol. 2002;29: 2327-36.

33. Husted JA, Tom BD, Farewell VT, Gladman DD. Longitudinal study of the bidirectional association between pain and depressive symptoms in patients with psoriatic arthritis. Arthritis Care Res. 2012;64: 758-65.

34. Li M, Soczynska JK, Kennedy SH. Inflammatory biomarkers in depression: an opportunity for novel therapeutic interventions. Curr Psychiatry Rep. 2011;13:316-20.

35. Lubrano E, Perrotta FM. Beyond TNF inhibitors: new pathways and emerging treatments for psoriatic arthritis. Drugs. 2016;76:663-73.

36. Von Korff M, Simon G. The relationship between pain and depression. Br J Psychiatry Suppl. 1996;30: 101-8.

37. Goldenberg D. The interface of pain and mood disturbance in rheumatic disease. Semin Arthritis Rheum. 2010;40:15-31.

38. Kekow J, Moots R, Khandker R, Melin J, Freundlich $\mathrm{B}$, Singh A. Improvements in patient-reported outcome symptoms of depression and anxiety, and their association with clinical remission among patients with moderate-to-severe active early rheumatoid arthritis. Rheumatology. 2011;50: 401-9.

39. Edwards RR, Cahalan C, Mensing G, Smith M, Haythornthwaite JA. Pain, catastrophizing, and depression in the rheumatic diseases. Nat Rev Rheumatol. 2011;7:216-24.

40. Michelsen B, Kristianslund EK, Sexton J, et al. Do depression and anxiety reduce the likelihood of remission in rheumatoid arthritis and psoriatic arthritis? Data from the prospective multicentre NOR-DMARD study. Ann Rheum Dis. 2017;76: 1906-10.

41. Betteridge N, Boehncke WH, Bundy C, Gossec L, Gratacos J, Augustin M. Promoting patient-centred care in psoriatic arthritis: a multidisciplinary European perspective on improving the patient experience. J Eur Acad Dermatol Venereol. 2016;30: 576-85.

42. Ballegaard C, Hojgaard P, Dreyer L, et al. Impact of comorbidities on tumor necrosis factor inhibitor therapy in psoriatic arthritis: a population-based cohort study. Arthritis Care Res. 2018;70:592-9.

43. Saad AA, Ashcroft DM, Watson KD, Hyrich KL, Noyce PR, Symmons DP. Persistence with anti-tumor necrosis factor therapies in patients with psoriatic arthritis: observational study from the British Society of Rheumatology Biologics Register. Arthritis Res Ther. 2009;11:R52.

44. Center for Drug Evaluation and Research. Clinical review: brodalumab (Siliq $\left.{ }^{\circledR}\right)$. Review completed August 25, 2016. http://www.accessdata.fda.gov/ drugsatfda_docs/nda/2017/761032Orig1s000MedR. pdf. Accessed 1 Apr 2020.

45. Lebwohl MG, Papp KA, Marangall LB, et al. Psychiatric adverse events during treatment with brodalumab: analysis of psoriasis clinical trials. J Am Acad Dermatol. 2018;78:81-9.

46. Zerilli T, Ocheretyaner E. Apremilast (Otezla): a new oral treatment for adults with psoriasis and psoriatic arthritis. P T. 2015;40:495-500.

47. Kavanaugh A, Gladman DD, Edwards CJ, et al. Long-term experience with apremilast in patients with psoriatic arthritis: 5-year results from a PALACE 1-3 pooled analysis. Arthritis Res Ther. 2019;21:118.

48. Brenner P, Citarella A, Wingard L, Sundström A. Use of antidepressants and benzodiazepine-related hypnotics before and after initiation of TNF-alpha inhibitors or non-biological systemic treatment in patients with rheumatoid arthritis, psoriatic arthritis or ankylosing spondylitis. BMC Rheumatol. 2020;4:9.

49. Cavanaugh J, Paterson C, McLean J, et al. Tumor necrosis factor blockade mediates altered serotonin transporter availability in rheumatoid arthritis: a clinical, proof-of-concept study. Ann Rheum Dis. 2010;69:1251-2.

50. Kirsch I. Placebo effect in the treatment of depression and anxiety. Front Psychiatry. 2019;10:407.

51. Raison CL, Rutherford RE, Woolwine BJ, et al. A randomized controlled trial of the tumor necrosis factor-alpha antagonist infliximab in treatment resistant depression: role of baseline inflammatory biomarkers. JAMA Psychiatry. 2013;70:31-41.

52. McIntyre RS, Subramaniapillai M, Lee Y, et al. Efficacy of adjunctive infliximab vs placebo in the treatment of adults with bipolar I/II depression: a randomized clinical trial. JAMA Psychiatry. 2019;76:783-90.

53. Fleming P, Roubille C, Richer V, et al. Effect of biologics on depressive symptoms in patients with 
psoriasis: a systematic review. J Eur Acad Dermatol Venereol. 2015;29:1063-70.

54. Wu C-Y, Chang Y-T, Juan C-K, et al. Depression and insomnia in patients with psoriasis and psoriatic arthritis taking tumor necrosis factor antagonists. Medicine (Baltimore). 2016;95:e3816.

55. Strand V, Sharp V, Koenig AS, et al. Comparison of health-related quality of life in rheumatoid arthritis, psoriatic arthritis and psoriasis and effects of etanercept treatment. Ann Rheum Dis. 2012;71: 1143-50.

56. Rosen CF, Mussani F, Chandran V, Eder L, Thavaneswaran A, Gladman DD. Patients with psoriatic arthritis have worse quality of life than those with psoriasis alone. Rheumatology (Oxford). 2012;51: 571-6.

57. Gladman D, Fleischmann R, Coteur G, Woltering F, Mease PJ. Effect of certolizumab pegol on multiple facets of psoriatic arthritis as reported by patients: 24-week patient-reported outcome results of a phase III, multicenter study. Arthritis Care Res. 2014;66:1085-92.

58. Gniadecki R, Robertson D, Molta CT, et al. Self-reported health outcomes in patients with psoriasis and psoriatic arthritis randomized to two etanercept regimens. J Eur Acad Dermatol Venereol. 2012;26:1436-43.

59. Meesters JJL, Petersson IF, Bergman S, Haglund E, Jacobsson LTH, Bremander A. Sociodemographic and disease-related factors are associated with patient-reported anxiety and depression in spondyloarthritis patients in the Swedish SpAScania cohort. Clin Rheumatol. 2014;33:1649-56.

60. Howells L, Chisholm A, Cotterill S, Chinoy H, Warren RB, Bundy C. Impact of disease severity, illness beliefs, and coping strategies on outcomes in psoriatic arthritis. Arthritis Care Res. 2018;70: 295-302.

61. Strober B, Gooderham M, de Jong EMGJ, et al. Depressive symptoms, depression and the effect of biologic therapy among patients in psoriasis longitudinal assessment and registry (PSOLAR). J Am Acad Dermatol. 2018;78:70-80.

62. Kotsis K, Voulgari PV, Tsifetaki N, et al. Anxiety and depressive symptoms and illness perceptions in psoriatic arthritis and associations with physical health-related quality of life. Arthritis Care Res. 2012;64:1593-601.

63. Lamb RC, Matcham F, Turner MA, et al. Screening for anxiety and depression in people with psoriasis: a cross-sectional study in a tertiary referral setting. Br J Dermatol. 2017;176:1028-34.
64. Milutinovic S, Veljkovic K, Zlatanovic M, Radunovic G, Damjanov N. Depression/anxiety symptoms in axial spondyloarthritis and psoriatic arthritis patients in Serbia: a pilot study. Rheumatol Int. 2019;39:1595-605.

65. Löfvendahl S, Jöud A, Petersson IF, Theander E, Svensson $\AA$, Carlsson KS. Income disparities in healthcare use remain after controlling for healthcare need: evidence from Swedish register data on psoriasis and psoriatic arthritis. Eur J Health Econ. 2018;19:447-62.

66. Di Carlo M, Becciolini A, Incorvaia A, et al. Mild cognitive impairment in psoriatic arthritis: prevalence and associated factors. Ann Rheum Dis. 2019;78[Suppl]:1271.

67. Lam RW, Kennedy SH, McIntyre RS, Khullar A. Cognitive dysfunction in major depressive disorder: effect on psychosocial functioning and implications for treatment. Can J Psychiatry. 2014;59: 649-54.

68. Bortolato B, Carvalho AF, Soczynska JK, Perini GI, McIntyre RS. The involvement of TNF- $\alpha$ in cognitive dysfunction associated with major depressive disorder: an opportunity for domain specific treatments. Curr Neuropharmacol. 2015;13:558-76.

69. McIntyre RS, Best M, Bowie C, et al. The THINCintegrated tool (THINC-it) screening assessment for cognitive dysfunction: validation in patients with major depressive disorder. J Clin Psychiatry. 2017;78:873-81.

70. Ott CV, Bjertrup AJ, Jensen JH, et al. Screening for cognitive dysfunction in unipolar depression: validation and evaluation of objective and subjective tools. J Affect Disord. 2016;190:607-15.

71. McIntyre RS, Anderson N, Baune BT, et al. Expert consensus on screening and assessment of cognition in psychiatry. CNS Spectr. 2019;24:154-62.

72. McIntyre RS, Woldeyohannes HO, Soczynska JK, et al. Anhedonia and cognitive function in adults with MDD: results from the International Mood Disorders Collaborative Project. CNS Spectr. 2016;21:362-6.

73. Cooper JA, Arulpragasam AR, Treadway MT. Anhedonia in depression: biological mechanisms and computational models. Curr Opin Behav Sci. 2018;22:128-35.

74. Uher R, Perlis RH, Henigsberg N, et al. Depression symptom dimensions as predictors of antidepressant treatment outcome: replicable evidence for interest-activity symptoms. Psychol Med. 2012;42: 967-80. 
75. Franken IHA, Rassin E, Muris P. The assessment of anhedonia in clinical and non-clinical populations: further validation of the Snaith-Hamilton Pleasure Scale (SHAPS). J Affect Disord. 2007;99:83-9.

76. Hemming L, Haddock G, Shaw J, Pratt D. Alexithymia and its associations with depression, suicidality, and aggression: an overview of the literature. Front. Psychiatry. 2019;10:203.

77. Li S, Zhang B, Guo Y, Zhang J. The association between alexithymia as assessed by the 20-item Toronto Alexithymia Scale and depression: a metaanalysis. Psychiatry Res. 2015;227:1-9.

78. Chimenti MS, Fonti GL, Conigliaro P, et al. Evaluation of alexithymia in patients affected by rheumatoid arthritis and psoriatic arthritis: a crosssectional study. Medicine. 2019;98(4):e13955.

79. Goerlich KS. The multifaceted nature of alexithymia-a neuroscientific perspective. Front Psychol. 2018;9:1614.

80. Knight MJ, Baune BT. Cognitive dysfunction in major depressive disorder. Curr Opin Psychiatry. 2018;31:26-31.

81. Ragguett R-M, Tamura JK, McIntyre RS. Keeping up with the clinical advances: depression. CNS Spectr. 2019;24(S1):84.

82. Castanheira L, Silva C, Cheniaux E, Telles-Correia D. Neuroimaging correlates of depression-implications to clinical practice. Front Psychiatry. 2019;10:703.

83. Sheline YI, Price JL, Yan Z, Mintun MA. Restingstate functional MRI in depression unmasks increased connectivity between networks via the dorsal nexus. Proc Natl Acad Sci USA. 2010;107: 11020-5.
84. Zhu X, Wang X, Xiao J,et al. Evidence of a dissociation pattern in resting-state default mode network connectivity in first-episode, treatment-naïve major depression patients. Biol Psychiatry. 2012;71:611-7.

85. Bremmer JD, Narayan M, Anderson ER, Staib LH, Miller HL, Charney DS. Hippocampal volume reduction in major depression. Am J Psychiatry. 2000;157:115-8.

86. Rot MAH, Mathew SJ, Charney DS. Neurological mechanisms in major depressive disorder. Can Med Assoc J. 2009;180:305-13.

87. Shen J, Tumonis T, van der Veen JW, Drevets WC, Meyers N, Hasler G. Reduced prefrontal glutamate/ glutamine and gamma-aminobutyric acid levels in major depression determined using proton magnetic resonance spectroscopy. Arch Gen Psychiatry. 2007;64:193.

88. Rush A, Trivedi MH, Ibrahim HM, et al. The 16-item quick inventory of depressive symptomatology (QIDS), clinician rating (QIDS-C), and self-report (QIDS-SR): a psychometric evaluation in patients with chronic major depression. Biol Psychiatry. 2003;54:573-83.

89. Snaith RP, Hamilton M, Morley S, Humayan A, Hargreaves D, Trigwell P. A scale for the assessment of hedonic tone the Snaith-Hamilton Pleasure Scale. Br J Psychiatry. 1995;167:99-103.

90. Spitzer RL, Kroenke K, Williams JBW, Löwe B. A brief measure for assessing generalized anxiety disorder. Arch Intern Med. 2006;166:1092-7.

91. Montgomery SA, Asberg M. A new depression scale designed to be sensitive to change. Br J Psychiatry. 1979;134:382-9. 